\title{
As praças públicas em Campos dos Goytacazes- RJ: dinâmica socioespacial e seus usos
}

\author{
Aline Sant Guimarães de Souza de Sant'Anna1
}

\begin{abstract}
Este apresenta os resultados de uma pesquisa sobre o espaço urbano de Campos dos Goytacazes a partir da praça pública. Por meio de levantamento bibliográfico e de características das praças públicas do Distrito Sede, de conversas informais com os usuários das praças, analisa-se a relação desses equipamentos, sua distribuição e os aspectos socioespaciais. A partir dos estudos de Gomes (2015), constatou-se uma relação entre o preço do solo, o padrão imobiliário ao entorno das praças, o estado de conservação dos equipamentos e as possibilidades de usos das praças de Campos dos Goytacazes. As praças que apresentaram melhores infraestruturas localizam-se nos bairros com mais altos preços do solo urbano e, portanto, indicam a desigualdade na cidade. Desse modo, melhores infraestruturas de praças e de acessibilidade são atrativos para as populações dos bairros mais carentes, os quais possuem praças que não apresentam boas condições de usos desses equipamentos.
\end{abstract}

Palavras-chave: Praças. Espaço urbano. Campos dos Goytacazes.

\section{The public squares in Campos dos Goytacazes - RJ: socio-spatial dynamics and their uses}

This article presents the results of a research about the urban space of Campos dos Goytacazes city, in Rio de Janeiro State, Brazil, from the public square. Through bibliographical survey, characteristics of the public squares of the city and informal conversations with users, was analyzed the relation between these equipment, your distribution and social and spatial aspects. From the studies of Gomes (2015), it was observed a relationship between the price of the soil, the standard real estate around the squares, the condition of the equipment and the possibilities of uses of squares of Campos dos Goytacazes. The squares that have best infrastructure are located in neighborhoods with the highest rates of urban land and therefore indicate inequality in the city. In this way, better infrastructure of squares and accessibility are attractive for the populations of the most needy neighborhoods, which have squares that do not present good conditions of uses of these equipments.

Key words: squares, urban space, Campos dos Goytacazes.

\section{Introdução}

A praça é o referencial urbano de espaço público voltado para o lazer e para o convívio. Historicamente compondo as cidades, as praças surgiram juntamente aos primeiros núcleos urbanos brasileiros, apresentando diversas funções ao longo do

\footnotetext{
1 Mestre em Geografia pela Universidade Federal Fluminense campus Campos dos Goytacazes (UFF). Email de contato: alinneguimaraes@yahoo.com.br
} 
tempo e reinventando-se enquanto espaço livre. Estão entre as funções das praças aquelas que possibilitam os usos religiosos, militares, comerciais, de circulação, de lazer, de embelezamento e, principalmente, de convivência.

Murillo Marx (1980, p.50) considera a praça como o "logradouro público por excelência", cuja criação no Brasil se deu a partir dos adros das igrejas. Saldanha (1993, p. 15) aponta a praça como "espaço maior, que revela a cidade e tende a confundir-se com ela", enquanto o jardim, um espaço privilegiado, pertencente a casas ou a edificações específicas, como os palácios, conventos, hospitais, entre outros. Saldanha (1993) também reafirma que a praça é caracterizada em todas as civilizações como um espaço público. Esse espaço público deve garantir a acessibilidade e o uso (Robba e Macedo, 2010). Dessa maneira, à medida que a praça de cada bairro possui equipamentos de qualidade, é facilitado o acesso devido ao curto deslocamento da população para desfrutar as funções que tais equipamentos podem proporcionar.

Considerando a praça como um espaço ancestral e que o seu surgimento está relacionado à origem ocidental do conceito de urbano (SEGAWA, 1996, p.31), o objetivo deste artigo é analisar as praças da cidade de Campos dos Goytacazes - RJ e, a partir de suas características materiais e dos aspectos socioespaciais, relacionar a qualidade desses equipamentos aos usos.

A análise dos aspectos infraestruturais das praças nos permite compreender, principalmente, a atuação do Estado na produção do espaço urbano, uma vez que esse é um dos agentes sociais da cidade (CÔRREA, 1995). Não desconsiderando o papel da população para a preservação dos espaços públicos, o Estado é o principal responsável pelas praças, pois atua por meio das ações reguladoras (como as leis de criação e de uso) e da execução de projetos urbanísticos que dotam o espaço da praça dos equipamentos de infraestrutura.

Campos dos Goytacazes, município com 4.026,696 km² de extensão, população estimada em 487.186 habitantes em $2016^{2}$, apresenta cerca de $90 \%$ da população urbana. Com 360.669 habitantes $^{3}$, ou seja, a maior população residente do município, e dotado das melhores infraestruturas urbanas (transporte, bancos, hotéis, praças etc.), o Distrito ${ }^{4}$ Centro ou Sede é a área de estudo desta pesquisa (Mapa 1). Nessa área, estão localizadas 89 praças implantadas, das quais 50 não possuem leis de criação especifica, mas são identificadas pelas secretarias municipais. Há também 9 praças instituídas por lei que ocupam terrenos vazios ou que não foram encontradas no endereço informado pela lei.

\footnotetext{
2 Dados do IBGE (Instituto Brasileiro de Geografia e Estatística).

3 Dados do CIDAC (Centro de Informações e Dados de Campos).

${ }^{4}$ O município de Campos dos Goytacazes possui 14 distritos de acordo com a divisão territorial datada de 1991: Dores de Macabu, Ibitioca, Morangaba, Morro do Côco, Mussurupe, Santa Maria, Santo Amaro de Campos, Santo Eduardo, São Sebastião de Campos, Serrinha, Tocos, Travessão, Vila Nova de Campos e Campos dos Goytacazes.
} 

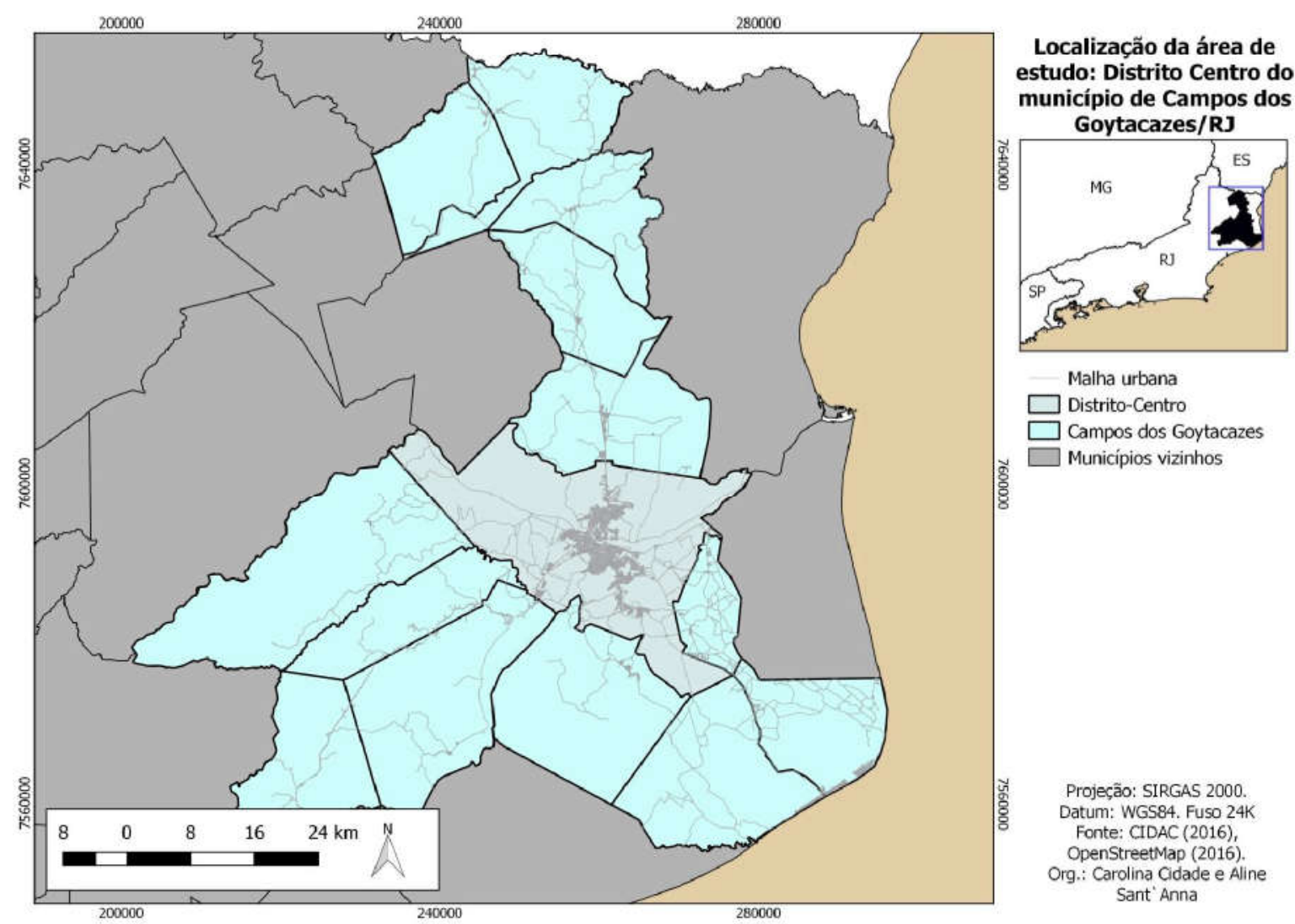

Malha urbana

Distrito-Centro

Campos dos Goytacazes

Municípios vizinhos

Projeção: SIRGAS 2000.

Datum: WGS84. Fuso 24K

Fonte: CIDAC (2016)

OpenStreetMap (2016).

Org.: Carolina Cidade e Aline Sant Anna

Mapa 1 - Localização da área de estudo: Distrito Sede do município de Campos dos Goytacazes

Esta pesquisa ocorreu por meio do trabalho de campo que possibilitou levantamento do perfil ao entorno das praças (sua topografia, formas e padrão das construções), dos equipamentos de infraestrutura das praças, assim como o status socioeconômico do bairro a partir da análise do padrão das edificações, bem como dos estudos de Gomes (2015) sobre o solo urbano.

A reflexão sobre os significados da praça, assim como a sua importância no contexto das cidades, com destaque para a produção do espaço urbano de Campos dos Goytacazes, ocorreu principalmente a partir da legislação urbana e da literatura de Marx (1980), De Angelis (2000), Faria (2000), Robba e Macedo (2010), Saldanha (1993), Segawa (1996) e Gomes (2005, 2015).

\section{As praças públicas de Campos dos Goytacazes no contexto histórico}

A produção do espaço urbano de Campos dos Goytacazes tem origem no núcleo urbano da vila de São Salvador, atual Distrito Sede, onde atualmente estão localizadas a catedral e a Praça São Salvador. Desde que se tornou vila em 1835, Campos dos Goytacazes se destacou por sua importância comercial e tornou-se uma área concentradora de infraestrutura e dos grupos sociais mais privilegiados.

Ao entorno da Praça São Salvador e da igreja, tornou-se sede da vila e foi construída "a Igreja matriz e junto a ela o cemitério, o pelourinho, a Casa de Câmara e a Cadeia" (POHLMANN, 2010, p.6), ou seja, edificações com características próprias da colonização portuguesa. Essa área central também foi equipada pelas intervenções urbanísticas ocorridas entre o final do século XIX e início do século XX. Os bancos, o ponto de bondes, a Câmara Municipal e a Biblioteca Municipal 
localizavam-se ao entorno da Praça São Salvador, e foi também no centro da praça que foi acesa, pela primeira vez em Campos, a luz elétrica, representando um momento do desenvolvimento técnico.

Faria (2000, p. 7) afirma que as intervenções urbanísticas, o que inclui projetos relacionados às praças, ocorreram nas áreas já valorizadas da cidade:

No início do século $X X$, são executados vários trabalhos nas partes privilegiadas da cidade: planejamento de praças, abertura de novas ruas, alargamento e prolongamento de ruas existentes, como também pavimentação, nivelamento, abertura de estradas (locais e intermunicipais), construção de edifícios públicos, de hospitais.

Faria (2000) considera que as reformas urbanísticas são marcadas por dois períodos: no primeiro, que ocorreu de 1915 a 1930, as prioridades foram a higiene e a saúde, destacando o Plano de Saturnino de Brito (1902), que para realizar a "limpeza" da cidade expulsou a população pobre da área central; já de 1915 a 1930, as atenções estavam voltadas para o embelezamento e a ampliação dos espaços. Espaços públicos como as praças e ruas receberam as ações sanitaristas, bem como arborização, que é um elemento de embelezamento urbano.

Diante das desigualdades sociais, ampliadas com a expulsão da população pobre para as áreas periféricas, foi criado o Plano Urbanístico de 1944, propondo a expansão urbana de novos bairros (como parte de Guarus, Turf, Saco e Matadouro), com os termos do contrato assinado pela firma Cia Coimbra Bueno Limitada e publicado em 21 de junho, no Monitor Campista. O contrato resumia-se a: - execução de planos de urbanização da cidade e planejando de uma parte
do distrito de Gaurús [sic] pesquisa sobre as possibilidades de evolução da
cidade respeitando os elementos de valor histórico e pitoresco; sistema de
transporte, viário, de esgotos, e de galerias pluviais, novos edifícios
públicos, estabelecimento de diversas zonas especializadas: comercial,
industrial, administrativa, de lazer, operária, etc.; preservação do meio
ambiente; construção de um parque municipal e um hipódromo, (...).
(FARIA, 2000, p.12)

Num contexto de crise da lavoura do café e de aumento da ocupação da zona urbana, houve a intensificação da favelização entre os anos de 1950 e 1960. Buscando atender as irregularidades urbanas, como o aumento das áreas das favelas, foi elaborado o Plano Urbanístico de 1979, também com o objetivo de ordenar a expansão urbana. No entanto, o plano não conseguiu atender ao que se propôs, principalmente no que se refere a atender às áreas mais carentes de infraestrutura, como, por exemplo, a região de Guarus, que historicamente apresenta baixos investimentos nos serviços públicos básicos.

As legislações subsequentes (Lei Orgânica Municipal de 1990/2014, Plano Diretor Municipal de 1991/2008, Leis de Uso e Ocupação do Solo Urbano e a Lei de Parcelamento e Uso de Solo) não promoveram ações, por parte do poder público, capazes de melhorar significativamente as condições de uso dos espaços públicos das praças para a população, mesmo no contexto de riqueza econômica, gerada pelos royalties do petróleo para o município a partir dos anos 1970.

A Lei Orgânica de 1990, no artigo 46, recomenda a revisão das nomenclaturas das praças, ruas e demais logradouros urbanos, ou seja, não versando sobre outros aspectos da organização (como a infraestrutura, as leis de 
criação, os usos etc.) desses espaços públicos. Essa lei é revisada pela Lei Orgânica de 2014 e aponta, em seu artigo 187, que o município deve adequar os espaços adensados às infraestruturas e aos equipamentos comunitários. $O$ artigo 294 da mesma lei define o Poder Executivo, juntamente com participação da comunidade, como o responsável por determinar os espaços públicos para construção de áreas destinadas ao lazer.

O Plano Diretor de 1991, uma proposta para ordenação do território e a expansão urbana, prevê a necessidade de preservação das praças que são patrimônios históricos e dos prédios que estão ao entorno delas, o que inclui a Praça São Salvador e o entorno das Praças Nilo Peçanha, da República e da Bandeira. Essa lei foi revista com o a criação do Estatuto da Cidade em 2001 e atualizada com o Plano Diretor Municipal de 2008.

Em relação aos espaços públicos, o Plano Diretor Municipal de 2008 prevê a necessidade de sua requalificação para valorização da cultura, de práticas esportivas e a melhoria da acessibilidade dos transportes. A praça é um dos elementos para a melhoria dos serviços urbanos. O Plano também trata da necessidade de coibição e controle das ocupações permanentes em espaços públicos por qualquer atividade ou edificação.

Leis complementares ao Plano Diretor de 2008, a Lei de Uso e Ocupação do Solo Urbano (Lei No 7.974, de 10 de dezembro de 2007) e a Lei de Parcelamento do Solo (Lei $n^{\circ} 7.975$, de 12 de dezembro de 2007) versa quanto à regulação dos espaços públicos urbanos de Campos dos Goytacazes, sem muitas especificações. A primeira legislação trata a praça como um equipamento comunitário e, diante da implantação desse equipamento, o poder público poderá transferir o direito de construir do proprietário para outro local. A segunda lei, no artigo 27 , define que o mínimo de terras destinadas ao uso público é de $35 \%$ do total da gleba, e $15 \%$ das áreas destinadas ao uso público excluem o sistema viário e as faixas de domínio. Há também a preocupação das praças públicas tornarem-se espaços para a implantação de áreas verdes, com pelo menos $6 \%$ da gleba destinada para esse fim, embora isso não esteja ocorrendo efetivamente nos últimos anos.

Apesar da importância da praça pública como espaço de representação dos aspectos históricos, econômicos e sociais, destacando-se em Campos dos Goytacazes a Praça São Salvador, que foi palco ainda de vários acontecimentos como a inauguração da luz elétrica no século XIX e, atualmente, dos frequentes eventos artísticos e políticos, chama a atenção a desigual distribuição das praças, bem como seu regular estado de conservação. Assim, considera-se a qualidade e a distribuição dos equipamentos de praças públicas, assim como seus usos, como elementos de análise socioespacial.

\section{As praças públicas de Campos dos Goytacazes: contexto socioespacial e qualidade de sua infraestrutura}

Buscando analisar a realidade contemporânea do espaço urbano de Campos dos Goytacazes a partir das praças públicas, esta pesquisa levantou dados na Secretaria de Praças e Jardins, a qual lista 149 áreas consideradas praças, localizadas em todo o município de Campos dos Goytacazes. As praças investigadas nesta pesquisa são as localizadas no Distrito Sede (ou Distrito Centro) de Campos dos Goytacazes, ou seja, as 89 praças encontradas nessa área, 
demonstram que a desigual distribuição das praças no município. As praças pesquisadas estão localizadas em 54 bairros, mas as áreas centrais e suas adjacências são as que mais concentram esses equipamentos públicos.

No Distrito Sede de Campos dos Goytacazes, $13,5 \%$ das praças estão localizadas em áreas de alto padrão imobiliário, $45 \%$ em áreas de médio padrão imobiliário, e $41 \%$ das praças em áreas de baixo padrão imobiliário. Gomes (2005) aponta ser comum na sociedade brasileira a maior parte dos equipamentos urbanos estar localizada nas áreas em que a população tem rendas média ou alta. Dessa forma, as praças de Campos dos Goytacazes enquadram-se nesse perfil, uma vez que $58,5 \%$ delas estão localizadas em áreas de médio e alto padrão imobiliário.

Quanto ao uso e ocupação do solo, foram considerados os usos residencial, comercial, industrial e misto. As praças estão localizadas em bairro predominantemente residencial $(66,3 \%)$, seguido por comercial $(18 \%)$ e misto $(15,7 \%)$, e não há praças que tenham ao seu entorno áreas industriais. A concentração das atividades comerciais do bairro ao entorno de algumas praças, bem como o fato de os imóveis que estão imediatamente ao entorno da praça apresentarem, em muitos casos, melhores condições do que os do restante do bairro, mesmo nos bairros mais carentes, revelam que as praças ainda exercem centralidade no espaço urbano.

As construções horizontais destacam-se ao entorno das praças, perfazendo $83,2 \%$, ao passo que $10,1 \%$ das edificações são verticais e $6,7 \%$ são mistas (horizontais e verticais). Bairros do Flamboyant, Centro e Pelinca são os que apresentam maior verticalização, por causa de sua estrutura urbanística bem dotada de infraestrutura de serviços e comércios. Já nas áreas periféricas predominam as residências horizontais.

A topografia das praças foi considerada um elemento de análise, uma vez que essa característica influencia a alocação dos equipamentos, pois equipamentos esportivos (quadras, campos de futebol etc.) são mais bem alocados em terrenos planos. Seguindo a topografia do restante da cidade, as praças são predominantemente planas $(85,4 \%)$ e de leve declividade (14,6\%). As formas geométricas das praças pesquisadas são: retangulares $(33,7 \%)$, quadrangulares $(19,1 \%)$, triangulares (18\%), circulares $(4,5 \%)$ e "outra" $(24,7 \%)$. A forma "outra" caracteriza as praças que tiveram seu desenho geralmente alterado por obras públicas.

Além do perfil imobiliário das adjacências das praças e as suas formas (topografia e desenho geométrico etc.), atributos mais difíceis de serem alterados, uma vez que dependem tanto de aspectos naturais quanto de aspectos socioeconômicos da produção do espaço, foram considerados, nesta pesquisa, os equipamentos infraestruturais (conforme a Tabela 1) que são alterados mais facilmente, como os bancos, brinquedos infantis, lixeiras, etc. Os tipos de equipamentos existentes e o seu estado de conservação são importantes para a avaliação das praças, pois podem fazer que estes espaços cumpram sua função social e de lazer, bem como torná-los atraentes para a população. A tabela a seguir apresenta os equipamentos das praças públicas e o seu estado de conservação: 
Tabela 1- Infraestrutura das praças públicas em Campos dos Goytacazes - 2016

\begin{tabular}{|c|c|c|c|c|c|}
\hline \multirow[t]{3}{*}{ Equipamentos } & \multicolumn{5}{|c|}{ Praças (\%) } \\
\hline & \multirow[t]{2}{*}{ Existente } & \multirow[t]{2}{*}{ Inexistente } & \multicolumn{3}{|c|}{ Conservação } \\
\hline & & & Boa & Regular & Ruim \\
\hline Banco & 83,2 & 16,8 & 22,5 & 45 & 15,7 \\
\hline Mesa com cadeiras & 35,9 & 64,1 & 15,7 & 13,5 & 6,7 \\
\hline Sanitário & 21,3 & 78,7 & 4,5 & 10,1 & 6,7 \\
\hline Bebedouro & - & 100 & - & - & - \\
\hline Lixeira & 47,2 & 52,8 & 23,6 & 19,1 & 4,5 \\
\hline Telefone público & 19,1 & 80,9 & 12,4 & 5,6 & 1,1 \\
\hline Placa de identificação do logradouro & 20,2 & 79,8 & 11,2 & 5,6 & 3,4 \\
\hline Ponto de táxi & 4,5 & 95,5 & 4,5 & - & - \\
\hline Ponto de ônibus & 14,6 & 85,4 & 6,7 & 4,5 & 3,4 \\
\hline Estacionamento próximo & 21,3 & 78,7 & 20,2 & 1,1 & - \\
\hline Palco/coreto & 9,0 & 91 & 5,6 & 2,3 & 1,1 \\
\hline Lago/lagoa, córrego/chafariz & 3,4 & 96,6 & 3,4 & - & - \\
\hline $\begin{array}{l}\text { Monumento decorativo (estátua, } \\
\text { busto, etc.) }\end{array}$ & 15,7 & 84,3 & 7,8 & 4,5 & 3,4 \\
\hline Estrutura de uso infantil & 59,5 & 40,5 & 13,5 & 24,7 & 21,3 \\
\hline Quiosque & 25,8 & 74,2 & 18 & 5,6 & 2,2 \\
\hline Lanchonete & 12,3 & 87,7 & 6,7 & 5,6 & - \\
\hline Equipamento de ginástica & 18 & 82 & 4,6 & 5,6 & 7,9 \\
\hline $\begin{array}{l}\text { Edificação de uso institucional } \\
\text { (guarita, capela, depósito etc.) }\end{array}$ & 18 & 82 & 13,5 & 4,5 & 0 \\
\hline $\begin{array}{l}\text { Estrutura esportiva (quadras, campo } \\
\text { etc.) }\end{array}$ & 39,3 & 60,7 & 9,0 & 18 & 1,3 \\
\hline Pista de skate & 7,9 & 92,1 & 3,4 & 3,4 & 1,1 \\
\hline Outro: Bicicletário & 28 & 72 & 28 & - & - \\
\hline Iluminação & 88,8 & 11,2 & & & \\
\hline
\end{tabular}

Fonte: Trabalho de Campo, mar./maio de 2016.

Org. Aline Guimarães de Souza Sant'Anna (2016). 
Calçadas, iluminação e equipamentos de lazer, como bancos, estruturas infantis e esportivas, são considerados infraestruturas básicas de praças, pois permitem os usos elementares das praças (GOMES, 2005). Equipamentos de contemplação, os bancos e a iluminação estão, respectivamente, em 83,2\% e 88,8\% das praças. Estruturas de lazer infantil estão em $59,5 \%$, e estruturas esportivas em $39,3 \%$ das praças.

Segundo Gomes (2005), a existência ou não de um equipamento em uma praça não interfere no uso da população, desde que atenda a sua necessidade mais ampla. A iluminação é insuficiente em $40,5 \%$ das praças, podendo prejudicar o seu uso, uma vez que é essencial para o funcionamento das praças e das cidades durante a noite, conforme já destacaram De Angelis e Neto (2000). Os autores ainda chamam atenção para outro equipamento básico para as praças, os bancos, que são importantes para conversar, sentar, descansar e tomar sol. Dessa forma, os bancos proporcionam a comodidade para a população desfrutar dos espaços públicos.

De Angelis e Neto (2000, p.1447) consideram que "a cancha esportiva, parque infantil, estrutura para terceira idade, equipamentos para prática de exercícios físicos, e qualquer outra que permita o lazer ativo e/ou passivo" são estruturas importantes para atender à função de recreação e descanso. As estruturas esportivas estão em um percentual significativo das praças $(39,3 \%)$ e, geralmente, são compostas por quadras de areia, quadras poliesportivas, campo de futebol e, em pouquíssimos casos, pistas de skate (7,9\%). A Praça do Jardim Aeroporto (Figura 1), bairro de periferia pobre, tem uma quadra esportiva que não possui nem o solo adequado como exemplo de todo o seu estado de conservação ruim, enquanto a Praça do Cigano (Figura 2) exemplifica a praça com boas condições de uso que possui até um campo de futebol com grama sintética.

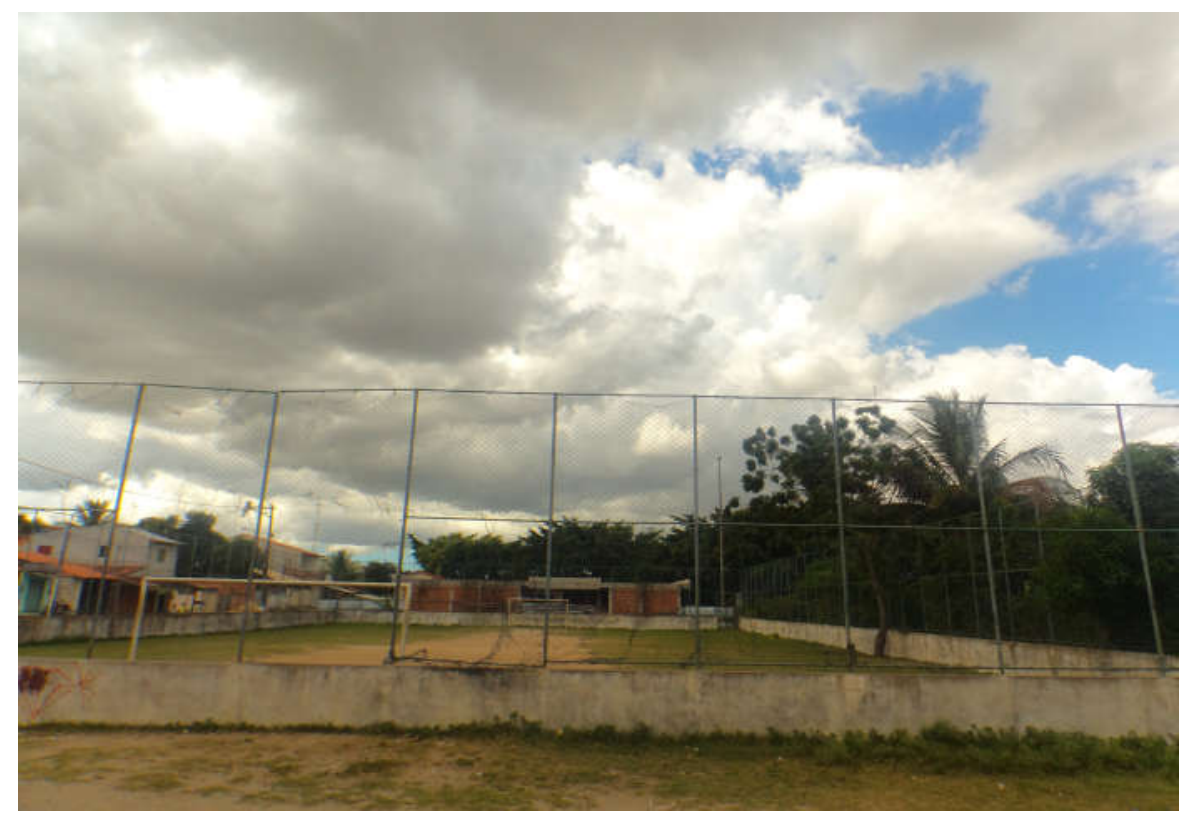

Figura 1 - Quadra da Praça do Bairro Jardim Aeroporto - 2016 Autora: ....(2016) 


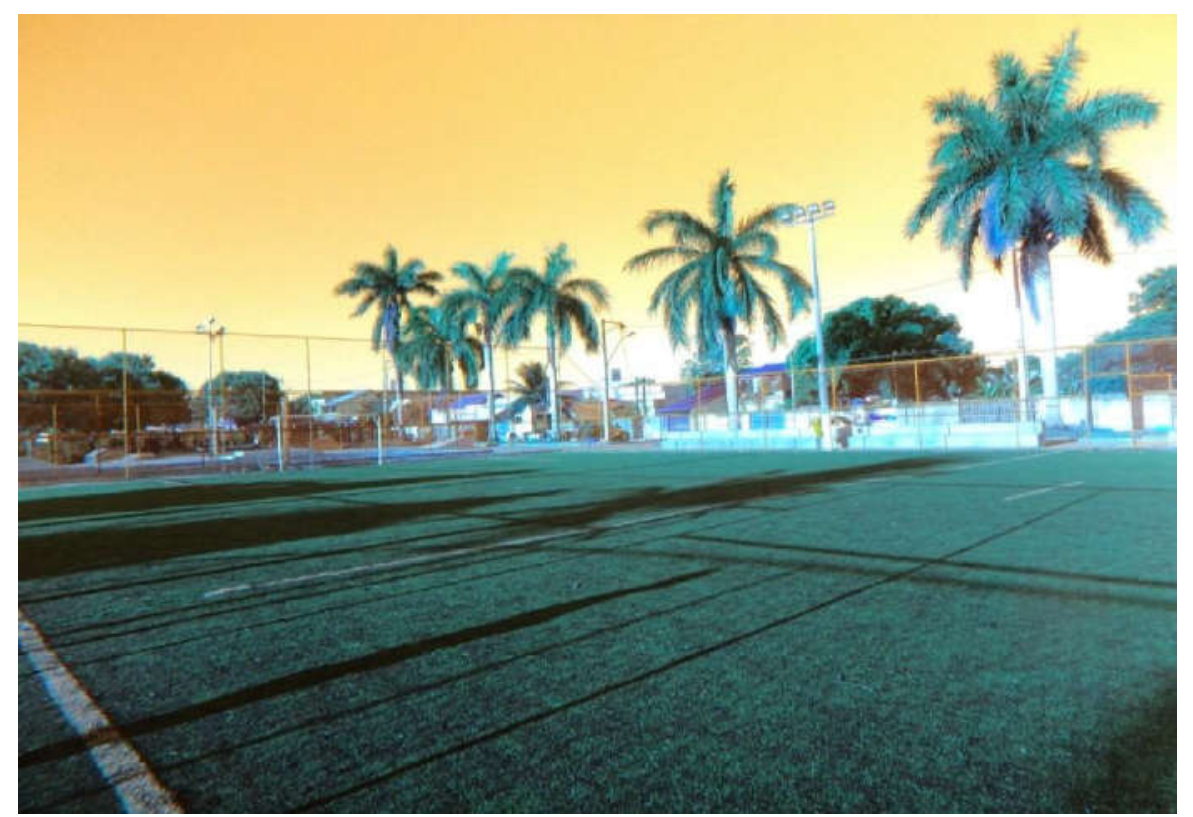

Figura 2 - Quadra esportiva da Praça do Cigano - 2016. Bairro: Julião Nogueira Autora: ... (2016)

Mesmo que não sejam essenciais às praças, a partir dos pontos de ônibus, bicicletários, pontos de táxi e estacionamentos, é possível avaliar o acesso às praças, bem como o grupo social que é beneficiado com tais transportes. Os dois primeiros são voltados para as classes de menor renda, enquanto o uso de táxi e de estacionamentos, para as classes com maior renda. As poucas praças com pontos de taxi $(4,5 \%)$, como as Praças São Salvador, Barão do Rio Branco e Tiradentes, por exemplo, estão localizadas nas áreas com médio e alto padrão imobiliário e maior preço do solo urbano. Dos estacionamentos existentes, $79 \%$ localizam-se em áreas com médio ou alto padrão imobiliário, como é o caso das Praças Almirante Tamandaré (Parque Tamandaré), Vereador José Renato Lima da Silva (Dr. Beda), Quatro Jornadas, Nilo Peçanha e Praça da Igreja São Benedito (Centro).

Os pontos de ônibus, em geral, estão localizados nos bairros mais pobres. $\mathrm{E}$ $76,5 \%$ das praças com bicicletários possuem baixo padrão imobiliário ao seu entorno. Vale destacar que é perceptível em Campos dos Goytacazes o uso de bicicletas como transporte, principalmente, para o trabalho da população de baixa renda. Esse uso é validado pela legislação urbana ${ }^{5}$ (municipal e estadual) e facilitado pelo relevo plano da cidade, mas as vias não oferecem condições de segurança e prioridade para os ciclistas.

Igrejas, centros de assistência social, espaços culturais (por exemplo, a "Academia Campista de Letras", na Praça Nilo Peçanha, e a "Casa de Cultura José Candido de Carvalho", na Praça da Paz, em Goitacazes (Figura 3), creches e escolas são as principais edificações institucionais presentes em $18 \%$ das praças de Campos dos Goytacazes. As edificações podem reduzir o espaço livre da praça e, também, possibilitar a melhoria da qualidade de alguns serviços essenciais, como a ampliação da escola para melhor atender a comunidade, que foi o caso da Escola

\footnotetext{
5 O Plano Diretor de 2008 de Campos dos Goytacazes (Lei 7.972) considera a implementação de ciclovias, ciclofaixas e bicicletários importante para garantir a acessibilidade no município. Para o artigo 177, a mobilidade urbana é efetuada a partir de medidas que inclui a implementação de ciclovias e o incentivo ao uso de bicicletas. As ciclovias são infraestruturas para a mobilidade urbana e devem estar entre as prioridades nas políticas municipais para atender à Política Nacional de Mobilidade Urbana, Lei 12.587 de 2012.
} 
Municipal Frederico Paes Barbosa, no Parque Novo Mundo, ou do Centro de Referência de Assistência Social ${ }^{6}$ (CRAS) do Parque Esplanada, por exemplo.

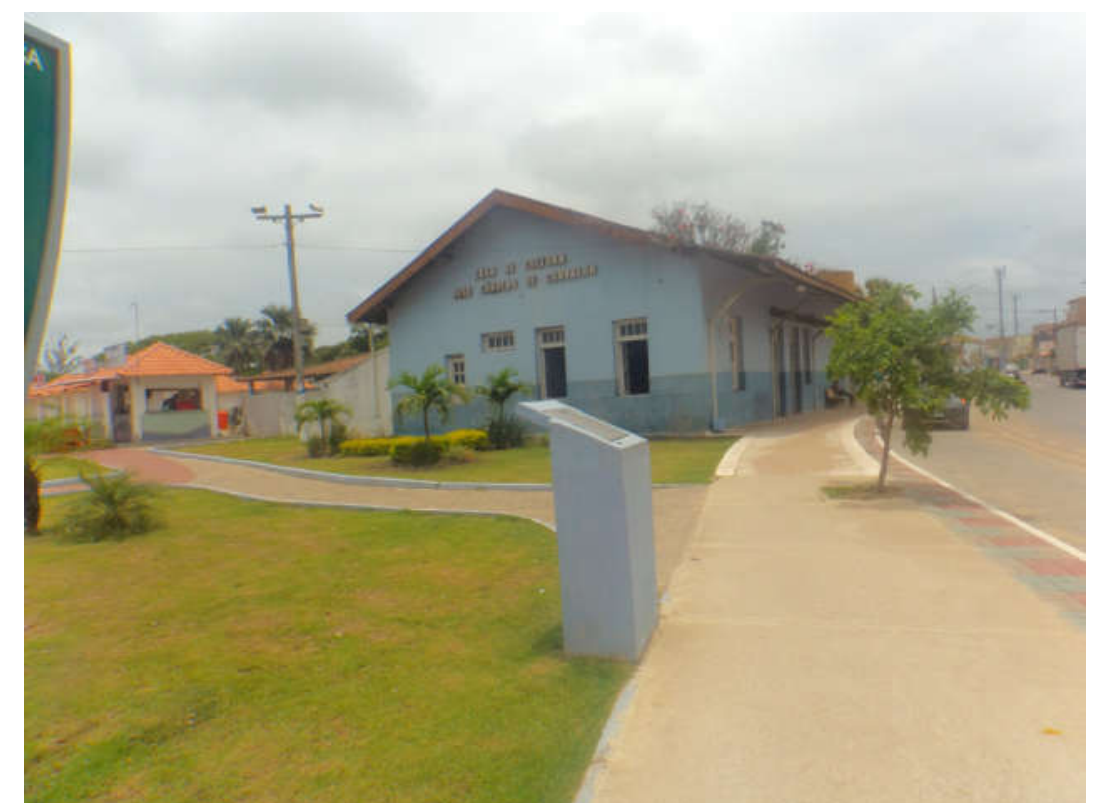

Figura 3 - Casa de Cultura José Candido de Carvalho, na Praça da Paz, em Goitacazes.Autora: ... (2016)

Palco/coreto, lago/lagoa/chafariz e monumentos, presentes em 9,0\%, 3,4\% e $15,7 \%$ das praças, respectivamente, são elementos de decoração e embelezamento da cidade e caracterizam um período histórico, o que justifica a maior presença em praças antigas, localizadas no centro e suas proximidades, como as Praças São Salvador (Figura 4), Quatro Jornadas, Barão do Rio Branco (Jardim do Liceu) e a Nilo Peçanha (Jardim São Benedito). As Praças do Carvão (nome fictício), Adalton Gomes, no bairro de Santa Cruz, e São Gonçalo, em Goitacazes estão entre as poucas praças periféricas que possuem elementos de embelezamento.

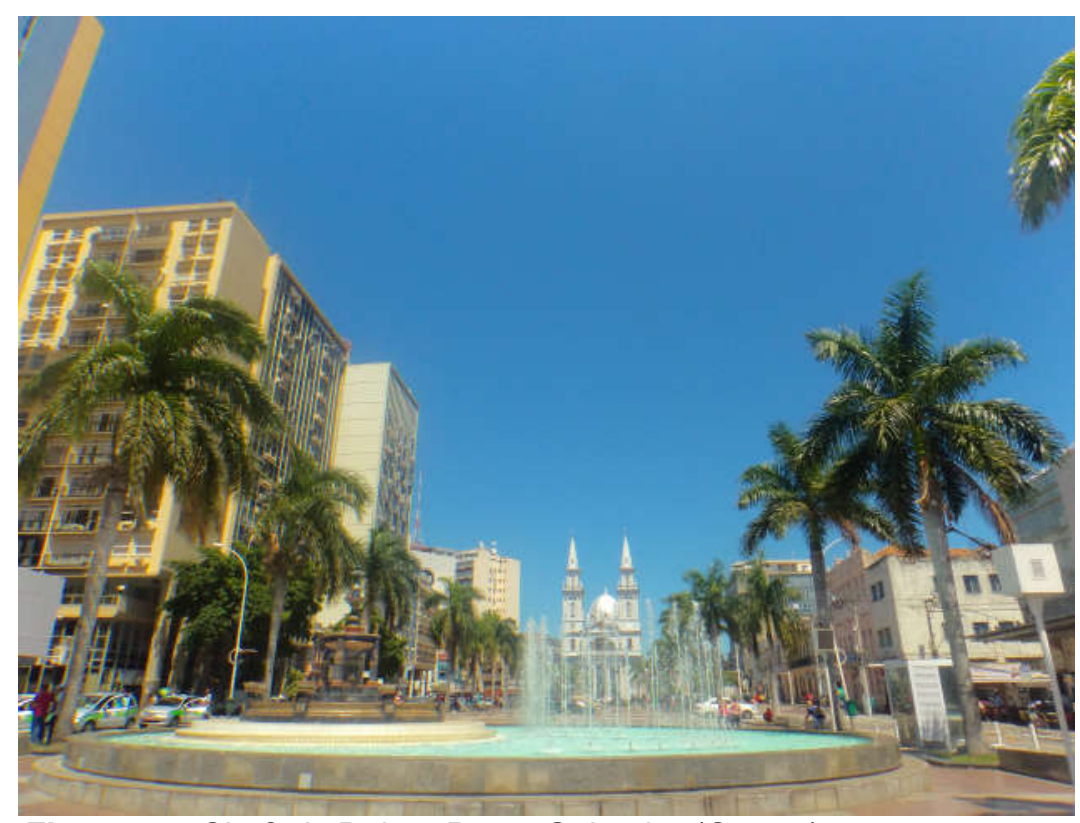

Figura 4 - Chafariz Belga, Praça Salvador (Centro)

${ }^{6}$ Unidade pública estatal de base territorial que atende as populações carentes ou de vulnerabilidade social. 


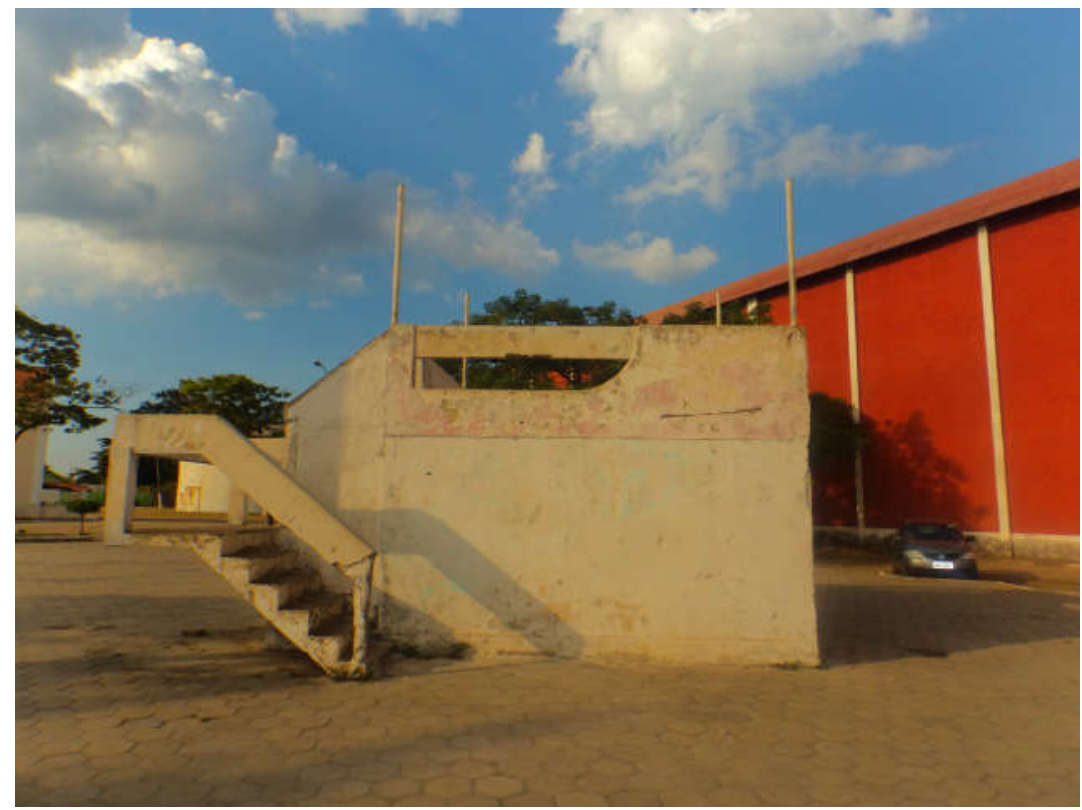

Figura 5 - Palco da Adalton Gomes (Bairro de Santa Cruz)

Autora: Aline Guimarães de Souza Sant'Anna (2016)

A vegetação também foi analisada, uma vez que é um elemento capaz de ampliar os usos e as funcionalidades da praça. Segundo Gomes (2005), a criação e a manutenção de espaços livres urbanos, como é o caso das praças e parques, são importantes para a qualidade ambiental e para a qualidade de vida. Ao mesmo tempo, deve-se considerar que a apropriação das áreas verdes pode ser um forma de agregar valor a uma propriedade privada, conforme destacou Henrique (2006). As praças bem arborizadas em Campos dos Goytacazes estão localizadas em áreas de elevado valor do solo urbano.

A vegetação está presente em $93,2 \%$ do corpus desta pesquisa. Entretanto, $67,4 \%$ das praças com vegetação não possuem árvores que proporcionem pelo menos $40 \%$ de sombra. Considerando que a vegetação traz muitos benefícios ${ }^{7}$ para os espaços urbanos, conforme já destacaram Loboda e De Angelis (2005), chamamos atenção para a deficiência das praças públicas de Campos dos Goytacazes em relação a esse aspecto, no que diz respeito à estética e à temperatura. A ausência de arborização contribui para a elevação da temperatura, o que dificulta a permanência das pessoas na praça.

Levando em consideração a composição, a distribuição e o estado de conservação dos elementos infraestruturais, $51,7 \%$ das praças de Campos dos Goytacazes apresentam aspecto paisagístico geral "regular"; 21,3 \%, "ruim"; 20,2 \%, "bom"; e 6,8\% das praças possuem o aspecto paisagístico "ótimo". A partir da associação da qualidade das praças aos estudos sobre a valorização do solo urbano em Campos do Goytacazes entre os anos de 1981 e 2011, realizados por Gomes $(2015)^{8}$, pode-se observar no mapa 2 que a qualidade da praça está relacionada à

\footnotetext{
7 Em resumo os benefícios das funções da vegetação: a melhoria da composição atmosférica, reduzindo a poluição do ar; manutenção do equilíbrio solo-clima-vegetação, ou seja, diminui as elevadas temperaturas, diminui a erosão do solo e o escoamento das águas das chuvas pelas áreas impermeáveis etc.; atenuação dos ruídos sonoros; além da melhoria estética urbana, por exemplo, com efeitos de bem-estar psicológico e valorização visual das áreas urbanas.

${ }^{8}$ Gomes (2015) setorizou a área urbana do Distrito Sede de Campos dos Goytacazes em Norte, Central, Sul, Leste e Oeste, de acordo com o preço do solo, considerando os grupos de bairros por suas características socioeconômicas e seu contexto histórico, uma vez que não há critérios oficiais de divisão administrativa.
} 
localização socioespacial, como demonstrou a observação do perfil imobiliário ao entorno das praças.
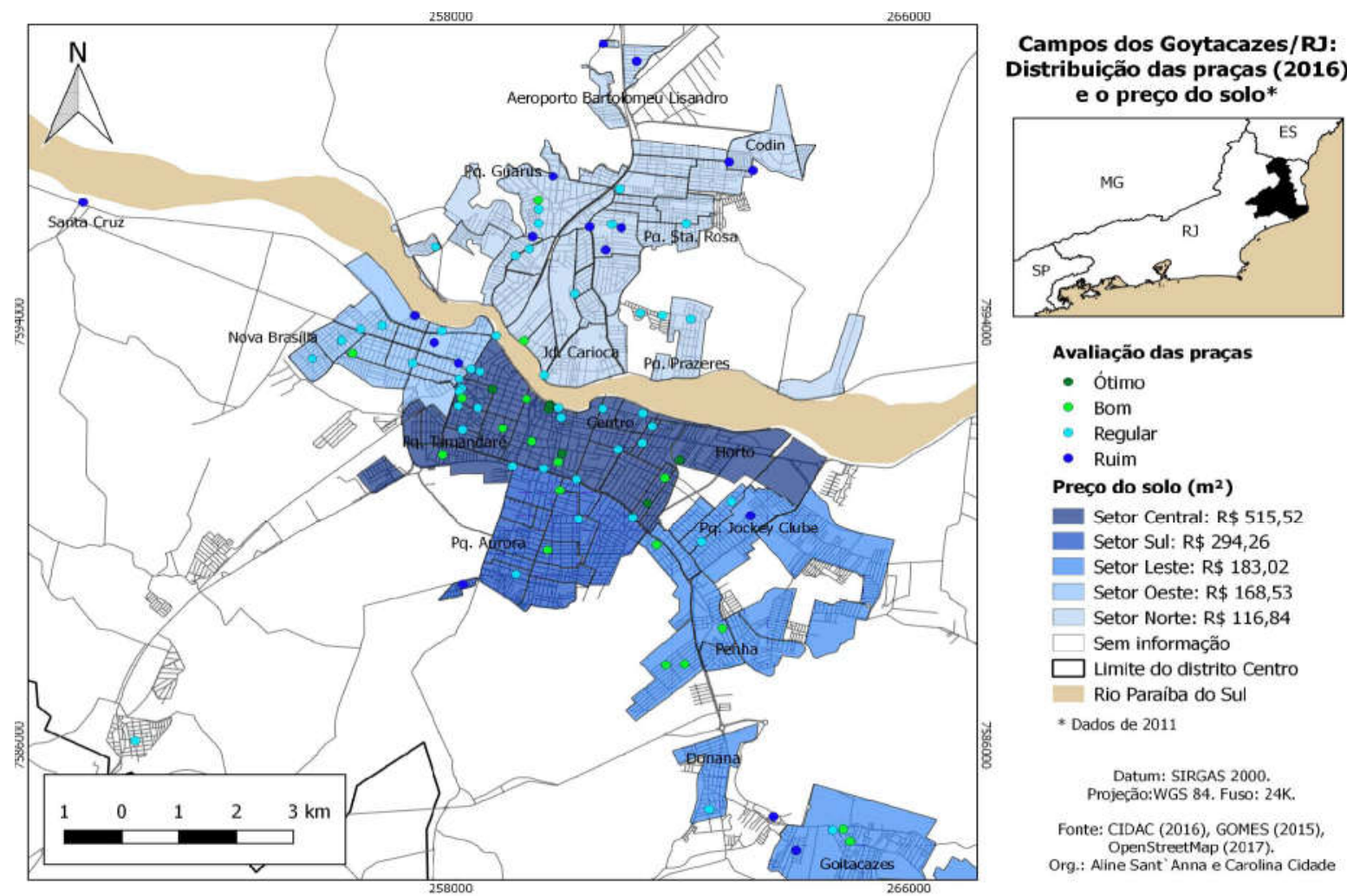

Mapa 2 - Campos dos Goytacazes/RJ: Distribuição das praças e preço do solo Fonte: CIDAC (2016), GOMES (2015). Orgs.: Carolina Cidade e Aline Sant'Anna (2016)

Historicamente valorizado, o Setor Central apresenta o mais elevado preço do solo. Esse é o setor que mais recebeu investimentos públicos e privados e onde estão concentrados serviços bancários, hotéis, shoppings centers, restaurantes, universidades, clínicas médicas, lojas especializadas etc. As praças com as melhores estruturas estão localizadas no Setor Central, tais como a Praça Nilo Peçanha e a Praça Barão do Rio Branco, localizadas no bairro Centro, e a Praça dos Trovadores, no Flamboyant.

Segundo Gomes (2015, p.37), os setores Leste, Oeste e Sul "apresentam um comportamento semelhante em relação às mudanças no preço do solo, ou seja, mesmo os bairros apresentando-se heterogêneos em relação à infraestrutura e conteúdo social, a média para estes setores são muito próximas". E a praça está entre estas infraestruturas heterogêneas.

Área de ocupação consolidada, o Setor Oeste apresenta praças predominantemente regulares, como as Praças Catulo da Paixão Cearense, no Bairro Caju, João 23, em Nova Brasília, Santa Terezinha e Bananeira, ambas no Bairro Pecuária.

O Setor Leste, de grande extensão territorial, de bairros bem afastados uns dos outros, caracteriza-se por apresentar praças bem heterogêneas, pois esses espaços possuem estado de conservação bom, regular e ruim com percentuais semelhantes. As praças do Residencial Santo Antônio, Manoel Soares da Silva, no bairro Penha, São Benedito e da Paz, ambas em Goitacazes, são praças com aspecto paisagístico bom. Entre as praças regulares, destacamos a Praça Santa Helena e a Praça Ana Salles, no Jockey Club. A Praça do Parque Saraiva, do 
Conjunto Habitacional de Goitacazes, e a Praça do Jockey II foram aquelas consideradas ruins.

O Setor Sul, que segundo Gomes (2015) é uma "área em dinamismo, em

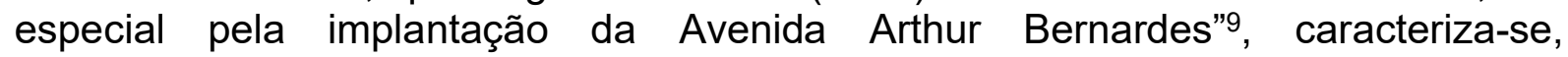
principalmente, por suas praças boas e regulares, exemplificadas, respectivamente, pela Praça do IPS (mesmo nome do bairro) e a Praça João XXIII (Parque Aurora).

Já o Setor Norte (Guarus), descrito por Gomes (2015, p.37) como "área deprimida, [...] um grande maciço de pobreza, com precários investimentos públicos em infraestrutura básica, como água, esgoto e asfalto, onde predominam loteamentos populares e ocupações irregulares," possui bairros muitos heterogêneos como os outros setores, mas as praças são de modo geral regulares e ruins. As praças do Parque Prazeres, do CQV (Parque Lebret) e São Cristovão (Jardim Carioca) estão entre as praças regulares nesse setor. A maior quantidade de praças com aspecto paisagístico ruim está localizada nesse setor. As praças do bairro da Codin e do Parque Santos Dumont, por exemplos, estão bastante deterioradas pelo tempo, pela falta de manutenção e por vandalismo. No entanto, como exceções, destacam-se as Praça Santo Antônio, no Jardim Carioca, e a Praça Ovídio Ferreira, no Parque Lebret, por apresentarem bom estado de conservação dos equipamentos infraestruturais.

De modo geral, embora os espaços públicos de praças estejam distribuídos em vários bairros, as praças mais bem equipadas estão localizadas ao entorno de áreas que tem o mais alto padrão imobiliário e o maior preço do solo urbano, enquanto que as praças com as piores condições infraestruturais estão relacionadas às piores condições de moradia.

\section{A relação entre infraestrutura das praças e seus usos}

Nesta pesquisa, foram escolhidas as São Salvador, no Centro, Nilo Peçanha (Jardim São Benedito), Centro, e a Praça dos Trovadores, no Flamboyant, para relacionar a sua infraestrutura aos seus usos, a partir dos critérios "aspecto paisagístico geral avaliado entre bom a ótimo" e "a intensa movimentação de pessoas". Para tal considerou-se a boa condição estrutural das praças e a valorização do solo urbano ${ }^{10}$.

Localizadas no Setor Central, as três praças estão em uma área de maior valor do solo urbano de Campos dos Goytacazes. Duas dessas praças, no caso, a São Salvador e a Nilo Peçanha, possuem fácil acesso a transportes como ônibus e táxis, o que possibilita contato com pessoas de vários bairros. A partir de conversas informais, foi possível verificar se há a utilização das praças por moradores de outros bairros, bem como, os motivos que provocaram o deslocamento das pessoas e se estão relacionadas ou não à infraestrutura. As seguintes questões orientaram as conversas com os usuários das praças:

- Em qual bairro você mora?

- O que te fez/faz escolher esta praça para frequentar?

\footnotetext{
9 A implantação da Avenida Arthur Bernardes (2005-2008) conectou áreas já valorizadas da cidade, estendendo-se do segmento Sudoeste (grande área do Boulevard Shopping) ao segmento Leste (área ao entorno do CEPOP- Centro de Eventos Populares), ou seja, tornando-se um novo corredor de investimentos imobiliários (GOMES, 2015).
}

10 Conforme demonstrado no mapa 2. 
- E para o caso da pessoa ser de outro bairro e este ter praça: Por que preferiu esta praça à do seu bairro?

Além das conversas informais, foram observados os usos da praça predominantes em cada turno, ou seja, de manhã na praça pode predominar uma função, de tarde e a noite outras ou, então, pode haver espaços demarcados por grupos específicos.

Na Praça São Salvador, localizada no Centro Histórico da cidade, predomina o espaço de passagem durante o dia, pois as palmeiras imperiais que estão ao seu entorno não proporcionam sombra, já à noite, a praça tornou-se um espaço de intensa frequência da população, após a reforma que retirou a sua vegetação em 2005. Os usos da praça foram alterados com a mudança de sua infraestrutura, uma vez que, antes da reforma, a praça era utilizada durante o dia pelos jovens para namorar e pelos idosos para se refrescar e ler jornais, e, atualmente, foram encontradas poucas pessoas da terceira idade à noite.

No período noturno, principalmente, nos finais de semana, a estrutura plana e sem obstáculo da Praça São Salvador reúne jovens e crianças para andarem de bicicleta, patins e skate. Ao entorno da praça, os casais namoram, famílias e amigos conversam sentados nos bancos. Há, simultaneamente, apresentações de dança no estilo hip hop que, segundo o grupo, também utiliza a praça para os seus ensaios durante a semana.

A Praça São Salvador é a que mais possibilita a acessibilidade de pessoas de outros bairros, pelas opções de transporte que possui, tais como serviços de táxi, de vans e de ônibus. Além disso, a praça está localizada próximo a um terminal de ônibus (Terminal Carlos Prestes), de onde saem várias linhas para os bairros da cidade. Parque Novo Mundo, IPS, Parque Aurora, Alphaville, Goitacazes, Jockey, Parque Guarus, Turf Club, Centro, Jardim Carioca estão entre os bairros dos quais foram encontrados representantes na Praça São Salvador.

As pessoas identificaram a beleza do ambiente, o uso infantil, a fresca e segurança como os principais atrativos para frequentarem a Praça São Salvador. Segundo os usuários, a movimentação das pessoas é importante para a segurança, pois as praças de outros bairros "ficam com poucas pessoas e têm assaltos" (informante). Uma das informantes foi apresentar a cidade para uma visita que estava em sua casa e escolheu a Praça Salvador, destacando-a como "o Centro de Campos”. De modo geral, a Praça São Salvador é escolhida pela população por sua infraestrutura, pelas opções de alimentação oferecidas pelo centro comercial próximo, Plaza Shopping, e o movimento, conforme destacou uma das informantes que participou das conversas: "é a única que tem o atrativo, o movimento e, por isso, vêm pessoas de toda a cidade".

Maior área de lazer a céu aberto e de variedade de equipamentos, a Praça Nilo Peçanha, no bairro Centro, mais conhecida como Jardim São Benedito, é gradeada, funciona de 7 às 22 horas e localiza-se em uma área privilegiada quanto ao acesso dos transportes públicos, pois está entre a rodoviária e o Terminal Carlos Prestes. Os usuários da Praça Nilo Peçanha que fazem uso de ônibus conseguem chegar a esse espaço de lazer a pé, em uns 10 minutos.

Com muitas possibilidades de lazer (equipamentos, infantis, academia de ginástica, quadras esportivas) e boa acessibilidade, a Praça Nilo Peçanha é mais frequentada nos turnos da manhã e da tarde pela população de diferentes bairros, tais como Ururaí, Santa Rosa, Parque Prazeres, Parque Vicente Dias, Parque 
Aurora, Jockey Club, Novo Jockey, Nova Brasília, Capão, Alphaville, Parque Califórnia, Flamboyant, Horto, Parque Rodoviário.

A segurança, apontada pelos usuários como "a tranquilidade", é um atrativo para a praça, pois, em alguns bairros, as pessoas deixam de utilizar as praças por medo da violência. Um morador do Parque Prazeres afirmou que seu bairro era violento e sua praça, um espaço de uso de drogas. Não se pode negar que ocorra essa prática na Praça Nilo Peçanha, mas a presença de funcionário no espaço, a ronda policial e a intensa movimentação, provavelmente, dificultam a ação do tráfico.

Alguns usuários da Praça Nilo Peçanha explicaram que levam seus filhos porque na sua infância também a frequentaram e, assim, demonstraram que esses espaços podem ser importantes para as relações de afeto. Essas relações são facilitadas pelos equipamentos infraestruturais e pela variada gama de atrativos que a praça possui: são brinquedos infantis (particulares ou públicos), lagos, quadras esportivas, monumentos, bancos, quiosque, ou seja, equipamentos que possibilitam usos como o lazer ativo, a contemplação, encontros (amorosos, familiares, religiosos etc.) e piqueniques.

Mais afastada das outras duas praças, a Praça dos Trovadores, no Flamboyant, está situada em uma área com menos acesso em relação ao transporte público, mesmo próxima à Avenida 28 de março, umas das mais importantes da cidade, é considerada "escondida". Essa praça é mais frequentada pela população do próprio bairro, para a realização de atividades como caminhadas, corridas, contemplação e, especialmente, atividades infantis que ocorrem, principalmente, nos fins de semana. Já a outra praça do bairro, Praça Antônio Roberto Fernandes, por estar mais próxima aos bairros vizinhos, é mais frequentada pelos moradores desses bairros, principalmente, os do Jockey.

As condições infraestruturais estão relacionadas à movimentação da praça e ao uso efetivo desse espaço. A população dos bairros carentes e com más condições dos equipamentos de praças buscam frequentar as praças com melhores equipamentos e de fácil acessibilidade, principalmente quanto ao transporte público. No caso das Praças Nilo Peçanha e São Salvador, grande parte dos usuários são de bairros de periferia pobre. Desse modo, há pessoas com boas praças próximas aos seus bairros e que frequentam as três praças citadas por motivos particulares, mas a maior parte dos usuários busca pela praça pública de qualidade, que não é disponibilizada em seus bairros.

\section{Considerações Finais}

Este artigo buscou caracterizar as praças públicas da cidade de Campos dos Goytacazes- RJ quanto aos aspectos infraestruturais e socioespaciais, este no que se refere ao padrão imobiliário e ao preço do solo urbano. Tais aspectos foram relacionados às possibilidades de usos que a praça de qualidade pode oferecer para a população.

A partir do levantamento infraestrutural e das leis urbanísticas, foi possível verificar a histórica e atual desigualdade em relação à distribuição das praças e à qualidade dos seus equipamentos.

Das 89 praças efetivamente implantadas no Distrito Sede de Campos dos Goytacazes, $45 \%$ localizam-se em áreas com perfil imobiliário de padrão médio, e $51,7 \%$ possuem aspecto paisagístico regular. As praças com aspecto regular estão em toda a cidade, mas as praças de melhor infraestrutura estão localizadas próximas às áreas valorizadas do Centro e do seu entorno, como as Praças São Salvador (Centro) e Jofre Maia (Horto). A maior parte dos bairros da periferia pobre 
apresenta praças carentes de infraestrutura, de elementos de embelezamento e de manutenção das estruturas existentes, como, por exemplo, as Praças da Comunidade do Oriente e as duas praças da Codin.

Assim, a pesquisa demonstrou que os equipamentos das praças e, consequentemente, os seus usos expressam as desigualdades socioespaciais da cidade, uma vez que as mais bem equipadas estão localizadas nas áreas de alto e médio padrão imobiliário e mais elevado preço do solo. As praças disponibilizadas para a população são capazes de proporcionar o uso desses espaços públicos, ocupando-os, trazendo movimento e "vida" para a cidade ou, então, o afastamento das pessoas dos seus bairros de moradia por causa da falta de condições infraestruturais.

\section{Referências}

CAMPOS DOS GOYTACAZES. Lei $n^{\circ} 7.974$, de 10 de dezembro de 2007. Institui a Lei de Parcelamento do Solo do Município de Campos dos Goytacazes. Campos dos Goytacazes, RJ.

Lei $n^{\circ} 7.975$, de 10 de dezembro de 2007. Institui A Lei de Uso e Ocupação do Solo Urbano do Município de Campos dos Goytacazes. Campos dos Goytacazes, RJ.

Lei $\mathrm{n}^{\circ}$ 7.972, de 31 de março de 2008. Institui o Plano Diretor do Município de Campos dos Goytacazes. Campos dos Goytacazes, RJ, 31 mar. 2008. p. 1-122. Disponível em: <http://www.campos.rj.gov.br/plano-diretor.php>. Acesso em: $5 \mathrm{dez}$. 2015. 130

.Lei Orgânica, de 28 de março de 1990. Lei Orgânica do Município de Campos dos Goytacazes. Disponível em: < em: 23 nov. 2016.

CORRÊA, R. L. O espaço urbano. 3. ed. São Paulo: Editora Ática, 1995. 94 p

DE ANGELIS, B. L.; ANGELIS NETO, G. Os elementos de desenho das praças de Maringá-PR. Acta Scientiarum, [s.i], v. 22, p.1445-1454, 28 nov. 2000. Disponível em:

Acesso em: 30 jun. 2016.

FARIA,T. P. As reformas urbanas de Campos e suas contradições. O plano de 1944: uma nova ordem social e urbana. CD-ROM dos Anais do $6^{\circ}$ Seminário de História da Cidade e do Urbanismo. Natal - RN. 2000. Online.

GOMES, M. A. S. As praças de Ribeirão Preto-SP: uma contribuição geográfica ao planejamento e à gestão dos espaços públicos. Dissertação (Mestrado em Geografia). Universidade Federal de Uberlândia. Uberlândia, 2005.

. A produção e a valorização desigual do espaço urbano em Campos dos Goytacazes-RJ: uma análise das ações do estado e dos promotores/incorporadores imobiliários. Revista Geografares: UFES. Vitória, 2015. 
HENRIQUE, W. A cidade e a natureza: a apropriação, a valorização e a sofisticação da natureza nos empreendimentos imobiliários de alto padrão em São Paulo. Geousp - Espaço e Tempo, São Paulo, v. 20, n. 2, p.65-77, 2006. Anual. Disponível em: < 2016.

LOBODA, Carlos Roberto; DE ANGELIS, B. L. D. Áreas verdes públicas urbanas: conceitos usos e funções. Ambiência: Revista do Centro de Ciências Agrárias e Ambientais, [s.i], v. 1, n. 1, p.125-139, jun. 2005. Semestral. Disponível em: $<$ >. Acesso em: 02 jul. 2016.

MARX, M. Cidade brasileira. São Paulo: Editora da Universidade de São Paulo, 1980. $151 \mathrm{p}$.

POHLMANN, M. A. R. de O.. Mudanças no Espaço Urbano e Gradual Transformação dos Referenciais Físicos da Memória da Cidade: a Praça São Salvador em Campos dos Goytacazes. 2010. Disponível em: <http://unuhospedagem.com.br/revista/rbeur/index.pho/shcu/issue/view/67>. Acesso em: 14 out. 2015.

ROBBA, F; MACEDO, S. S. Praças brasileiras: public squares in Brazil. São Paulo: Edusp:Imprensa oficial do Estado. 2002, 312p.

SALDANHA, N. O jardim e a praça. São Paulo: Edusp, 1993. 120

SEGAWA, H. Ao amor do público: Jardins no Brasil. São Paulo: Studio Nobel: Fapesp, 1996. 255 p. 